\title{
TUTORIAL: TOOLS AND METHODOLOGIES FOR EXECUTING SUCCESSFUL SIMULATION CONSULTING PROJECTS
}

\author{
Carley Jurishica \\ Rockwell Automation \\ 180 Harvester Drive, Suite 190 \\ Burr Ridge, IL 60527, USA
}

\author{
Nancy Zupick \\ Rockwell Automation \\ 2100 Corporate Drive, Suite 550 \\ Wexford, PA 15090, USA
}

\begin{abstract}
When problems are extremely complex, highly variable and too big for simple calculations, a simulation project solution should be considered. Not surprisingly, the resulting project endeavor will also be complex and should be managed with a clear strategy and attention to detail. This paper will extend beyond basic project tips by providing specific tools and methodologies to help simulation leaders execute successful simulation consulting projects inside or outside their organization.
\end{abstract}

\section{INTRODUCTION}

This paper is organized in three key sections, Gathering Requirements, Building the Model and Delivering Results. In the "Gathering Requirements" section we will highlight how to identify a project and move from an initial scope to a final detailed functional specification. The "Building the Model" section will provide specific tips for managing the model building effort. Finally, the "Delivering Results" section will focus on creating models that are easy for analysts to run scenarios and understand project results. Figure 1 provides a high-level view of the project life cycle and common deliverables from each phase. These phases and deliverables will be discussed in more detail throughout the paper.

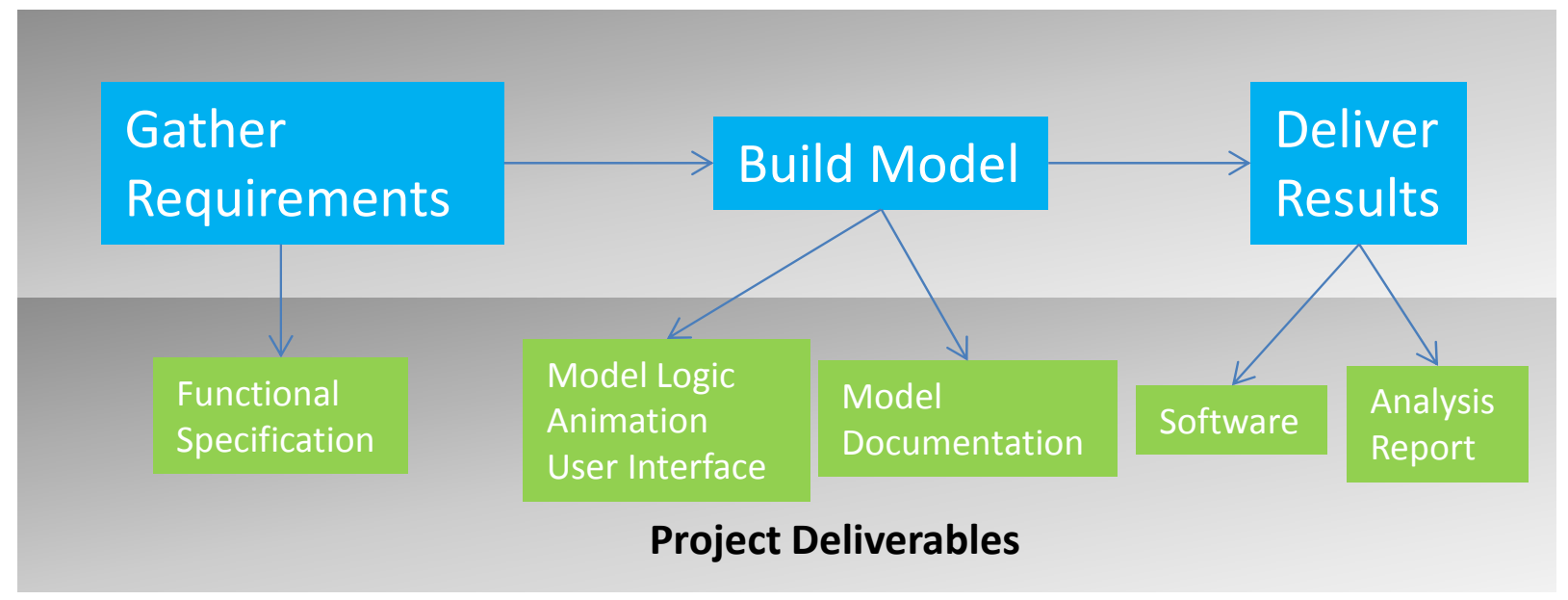

Figure 1: Simulation project phases and deliverables

Simulation is a vast field and may encompass a variety of interpretations. Throughout this paper, when we mention simulation, we are referring to a broad collection of methods and applications to mimic the behavior of real systems, usually on a computer with appropriate software (Kelton, Sadowski, and 


\section{Jurishica and Zupick}

Swets 2010). We have attempted to provide tools and methodologies that are independent of any particular software application. We do represent Arena simulation software from Rockwell Automation and in some instances the examples provided are specific to the Arena software application.

We will use various terms throughout this paper. Some key definitions are provided below.

Simulation Consulting Project Manager Individual responsible for managing the simulation pro ject and the simulation consulting team.

Simulation Consultant Any individual whose primary expertise is in executing simulation projects.

Client The end user of the simulation model or model information for the purposes of decisionmaking.

Simulation Consulting Project An engagement between the simulation consulting project manager and the client for the purpose of building a simulation model that will be utilized for decision making. Simulation Team Member Any individual involved directly or indirectly in the simulation consult ing project.

\section{GATHERING REQUIREMENTS}

\subsection{Is Simulation the right Tool?}

Simulation is another tool in your toolbox for problem solving. Not all problems will require or even benefit from a simulation study. Defining the problem and having a clear understanding of the project objectives should be the first step for the simulation team.

With a clear project objective, it can be determined which tools will help achieve the goals. Understanding how different tools and methodologies should and should not be applied is a necessary skill on any project team. As noted by Balci (2011), a large-scale M\&S (modeling and simulation) application development requires many areas of expertise including simulation modeling methodology, software engineering, statistics, systems analysis, project management, and problem domain-specific knowledge.

In Table 1 we provide a guideline for when simulation might be appropriate for a project. There are several common characteristics of simulation projects. These characteristics, along with example situations and why simulation is a good fit are provided.

Table 1: Guideline for determining if simulation is the right tool for a project.

\begin{tabular}{|l|l|l|}
\hline Characteristic & Example & Why Simulation? \\
\hline Highly Variable & $\begin{array}{l}\text { Healthcare. A healthcare manager } \\
\text { needs to determine the emergency } \\
\text { department (ED) bed capacity. The }\end{array}$ & $\begin{array}{l}\text { A key advantage of simulation is } \\
\text { the ability to handle variability. } \\
\text { ED has variable patient arrival rates } \\
\text { and variable staff service times. Var- }\end{array}$ \\
$\begin{array}{ll}\text { iability also exists in equipment fail- } \\
\text { tems. It disrupts systems. Without } \\
\text { variability, performance would of- } \\
\text { ten be easy to predict. Accurately } \\
\text { capturing system variability will re- } \\
\text { sult in better analysis and decision } \\
\text { making. }\end{array}$ \\
\hline
\end{tabular}




\begin{tabular}{|c|c|c|}
\hline $\begin{array}{l}\text { Process Interde- } \\
\text { pendencies }\end{array}$ & $\begin{array}{l}\text { Manufacturing. A plant manager has } \\
\text { been tasked to increase throughput by } \\
5 \% \text {. There are several areas that } \\
\text { might be improved, but she is unsure } \\
\text { on which area she should focus. If } \\
\text { she makes changes to improve the } \\
\text { performance of one machine on the } \\
\text { line, it is difficult to know how it will } \\
\text { impact the upstream and downstream } \\
\text { processes. }\end{array}$ & $\begin{array}{l}\text { Simulation allows analysts to study } \\
\text { system interactions. Processes } \\
\text { should not be analyzed in a silo. All } \\
\text { systems have interdependencies. } \\
\text { Users can change one or more vari- } \\
\text { ables in the model and clearly un- } \\
\text { derstand how the entire system is } \\
\text { impacted. }\end{array}$ \\
\hline $\begin{array}{l}\text { Identify Bottle- } \\
\text { necks }\end{array}$ & $\begin{array}{l}\text { Restaurant Drive-through. A fast } \\
\text { food restaurant has recently heard } \\
\text { complaints from customers about } \\
\text { how long they are waiting in the } \\
\text { drive-through line. Cars have been } \\
\text { balking and reneging from the line. } \\
\text { The manager would like to test add- } \\
\text { ing a lane and changing the way staff } \\
\text { handle customers prior to making the } \\
\text { real-world changes. }\end{array}$ & $\begin{array}{l}\text { Queueing theory is at the core of } \\
\text { simulation. The average time enti- } \\
\text { ties spend waiting for resources and } \\
\text { the average numbers of entities } \\
\text { waiting for a resource are key out- } \\
\text { put statistics of a simulation study. } \\
\text { These statistics are automatically } \\
\text { calculated by the simulation soft- } \\
\text { ware. Experiment with the model to } \\
\text { determine which changes will re- } \\
\text { duce the bottleneck in the real } \\
\text { world. }\end{array}$ \\
\hline $\begin{array}{ll}\text { Analysis } & \text { Over } \\
\text { Time } & \end{array}$ & $\begin{array}{l}\text { Airport Security. An airport chief } \\
\text { operations officer is trying to deter- } \\
\text { mine how to staff the airport security } \\
\text { checkpoint. Arrival of travelers to } \\
\text { security varies by time of year, day } \\
\text { of week and time of day. }\end{array}$ & $\begin{array}{l}\text { Simulation allows you to look at a } \\
\text { system dynamically over time. Re- } \\
\text { lying on average values for planning } \\
\text { can be misleading. Use simulation } \\
\text { to plan staff schedules and resource } \\
\text { availability by time of day, week or } \\
\text { any planning horizon. }\end{array}$ \\
\hline Animation & $\begin{array}{l}\text { Mining. A mining operations man- } \\
\text { ager needs to demonstrate the impact } \\
\text { of changing the number of trucks and } \\
\text { shovels on the overall mining } \\
\text { throughput. He would like to clearly } \\
\text { present to his management team the } \\
\text { system bottlenecks, resource utiliza- } \\
\text { tions over time and how future } \\
\text { changes will impact the overall sys- } \\
\text { tem using an animation of the mine. }\end{array}$ & $\begin{array}{l}\text { Animation builds confidence. See- } \\
\text { ing the system dynamically change } \\
\text { over time with realistic visuals cre- } \\
\text { ates system buy-in and agreement } \\
\text { among decision-makers. A valid } \\
\text { model, backed by real data and } \\
\text { compelling animation, will help } \\
\text { leaders to make decisions. }\end{array}$ \\
\hline
\end{tabular}




\begin{tabular}{|l|l|l|}
\hline $\begin{array}{l}\text { Process Com- } \\
\text { plexity }\end{array}$ & $\begin{array}{l}\text { Call Center. A call center manager } \\
\text { needs to improve the service level of } \\
\text { his call center. There are many dif- }\end{array}$ & $\begin{array}{l}\text { Simulation projects can handle } \\
\text { complexity. Simulation models are } \\
\text { dynamic and based on real-world }\end{array}$ \\
& $\begin{array}{l}\text { ferent types of callers. Callers speak } \\
\text { different languages. The request for } \\
\text { service may arrive to the call center } \\
\text { via email, fax or phone. It is difficult }\end{array}$ & $\begin{array}{l}\text { sions regarding complex systems } \\
\text { using a simple spreadsheet and av- } \\
\text { erage values can be dangerous. }\end{array}$ \\
& $\begin{array}{l}\text { for him to wrap his mind around all } \\
\text { the dynamic business rules. Deter- } \\
\text { mining the ideal staffing and process } \\
\text { flow is critical, but the complexity is } \\
\text { overwhelming. }\end{array}$ & $\begin{array}{l}\text { With highly complex systems, } \\
\text { simulation will provide more de- } \\
\text { tailed information to allow for better } \\
\text { decision making. }\end{array}$ \\
\hline
\end{tabular}

Sometimes the desire to apply simulation will cause individuals to apply it to all situations. This can result in a project being more complicated and costly than necessary and lead upper management to have a poor opinion of simulation. Simulation is powerful. Understanding when a project will and will not benefit is an important skill. Consult experienced simulation experts if you are not certain if simulation is the correct tool for a problem.

\subsection{Scope of Work}

Once it has been determined that simulation is a proper approach, the simulation team must scope the project and develop a detailed functional specification. The final functional specification will be a roadmap for model development and act as a written agreement among all simulation team members.

To ensure the final functional specification contains all key information, a formal process for requirements gathering is recommended. First, the simulation consulting project manager must work with the client to identify all process owners and participants that should be interviewed as a part of the information gathering exercise. We recommend a scope of work template, similar to the one provided in Table 2, as a starting point.

Table 2: The Scope of Work template is a guide for gathering requirement information. This information is used to create the functional specification that will serve as the project roadmap.

\section{Background}

Provide any background information on the company and problem.

Project Objectives

Define the goals of the study.

What questions are you trying to answer?

- Major capital expenditure decisions - Should we invest in new equipment?

- Bottlenecks - How can we reduce the queueing at the resource?

- Resource planning - What is the ideal staff schedule for the week?

- New system design - How should we layout the system? How much equipment do we need? How much inventory do we need?

- Major changes to an existing system - How will the changes impact the current system? How can we minimize the disruption and maximize the change effect? Is our design adequate? 


\section{Jurishica and Zupick}

Process Flow and System Specifications

In order to build a valid model, the simulation team must map out process. Regardless of the industry (healthcare, government, manufacturing, etc.) there is a movement of entities (people, widgets, orders, etc.) through the system. This flow must be documented.

Below are examples of leading questions to ask process owners and participants.

- How does an entity move through the system?

- What kind of constraints are in the system?

- What business rules need to be considered in this process?

- Are there exceptions to how an entity might be handled at different steps in the process?

- What types of bottlenecks currently exist in the system?

Ask a lot of questions during this phase! This is a significant time of system discovery during the project life cycle. Developing a final process flow chart using a professional diagramming application is highly recommended.

\section{"What-if" Scenarios}

Define the "what-if" scenarios that will be tested using the model. Understanding the questions that need to be answered by the model will be of particular importance to the model builder. This information will drive the detail and complexity of the model.

- What if we add new machines?

- What if we increase equipment speeds?

- What if we change our product mix?

- What if we change our resource schedules?

- What if we change our facility layout?

- What if the demand for our services changes?

- What happens if we change the capacity of our system?

- What if we modify specific business rules?

\section{Key Performance Indicators (KPI)}

Defining the KPIs is critical. When running "what-if” scenarios, these outputs will be compared among scenarios to assist with decision making. Below are some common KPIs.

- $\quad$ Resource utilizations

- Total throughput

- Work in process

- Cycle time

- Costs

- Shortages

- Time in queue

- Number in queue 
Animation Requirements

Define the simulation animation requirements. Depending on the simulation software used for the project, the animation opportunities will vary. It is important to define the animation expectations at the onset of the project.

Below are several options that may be available.

- Statistical reports only

- Live data dashboards including plots, charts and variable animation that update while the simulation runs

- 2D animation

- 3D animation

\section{Assumptions}

Managing the complexity of the simulation project and model is a developed skill. We can provide endless advice, but as noted by Sadowski (1991), there is no substitute for experience. Knowing what details to include and exclude from the model must be defined and agreed on. Having written documentation of the project assumptions is important. Below are some generic sample assumptions.

- The model assumes that all resources behave the same. The model will not be concerned that different workers that have different skills.

- Rare weather events that may disrupt operations will not be modeled.

- There is an infinite supply of raw materials. This is not a constraint in the operation and we will assume there is always availability of raw materials.

\section{Deliverables}

Define the final project output. The simulation consulting project manager and the client must agree on specific deliverables before the project begins. Below are possible deliverables.

- Functional specification

- This document will serve as a contract between the simulation project manager and the client. All known details about the project should be documented in the functional specification.

- Simulation model logic

- Simulation model animation

- Model documentation

- User interface

- Simulation consultants may develop an easy-to-use interface for entering data and reviewing results.

- $\quad$ Software licensing

- If the client will be running scenarios on their own, they will need access to the model and software to run the model.

- Analysis report

- A detailed report of all scenarios runs and results. Specific recommendations to system improvements based on the results of the scenario analysis may be included.

The scope of work template requires input from many different simulation team members. System managers, model builders, key stake holders and people working in the system will all have insights. 


\section{Jurishica and Zupick}

This phase of the consulting engagement can be quite eye-opening. New system pain points, processes and behaviors are often discovered when the team is forced to look at the process in such detail.

\subsection{Functional Specification}

With the scope of work information, the simulation consulting team is now ready to develop a detailed functional specification. Whether the consulting project is between two parties in the same organization or between two different companies, a functional specification should be developed. All details from the scope will be clearly defined in the functional specification. Below are the key sections, at a minimum, to include in the functional specification.

- Project sign off agreement*

- Background

- Project objectives

- Process flow and system specifications

- "What-if" scenarios

- Key performance indicators

- Data requirements*

- Animation requirements

- Assumptions

- Deliverables

- Timeline*

- Payment terms*

- Additional terms and conditions*

Many of these sections have been discussed as a part of the scope of work, but several new areas are needed for the functional specification. The new areas are noted in the list above with an asterisk "*”.

A critical part of the functional specification is the project sign-off agreement. The simulation consulting project manager and the client must sign the functional specification. This ensures that both parties agree on the purpose of the project and all details surrounding the simulation model. As Sadowski (1991) notes, the simulation consulting project manager needs to know what the client expects and the client needs to know what the simulation consulting project manager will deliver. If a new request regarding the project surfaces, an addendum to the functional specification should be created and signed. Figure 2 provides a sample project sign off agreement.

\section{Project Sign Off Agreement}

[Client] agrees to engage with [simulation consultants] to develop a simulation model per the specifications provided in this document. [Insert any additional detail regarding project]

Client Name

Title

Company

Simulation Consulting Project Manager Name

Title

Company
Date

Date

Figure 2: Project sign off agreement 


\section{Jurishica and Zupick}

Once the project has been defined, a timeframe for the simulation project should be estimated. The estimated timeframe along with milestone dates should be established. A regular meeting schedule should also be agreed on between the simulation consulting project manager and the client to ensure the project stays on track. Dates should be adjusted as necessary throughout the life of the project.

Depending on the nature of the engagement, project payment terms may be necessary. The payment terms should be included with the functional specification. They provide the total cost to the client for the described project.

Finally, the functional specification should include any additional terms and conditions. Figure 3 provides example terms and conditions. Any particular legal terms that may need to exist between companies can also be listed in this section.

\section{Simulation Terms and Conditions}

1. The client agrees to supply all requested data and information supporting this project to the simulation consultants in a timely manner. The simulation consultants will provide a complete list of requirements during the initial kickoff.

2. The client agrees to provide a single project management contact. This point of contact will facilitate project meetings, arrange for on-site interviews, and ensure that project reviews and meetings are conducted in a timely manner.

3. Changes to the scope of work requested by the client throughout the duration of the project will be immediately identified and communicated through simulation project manager. This prevents schedule overruns due to unnoticed changes in the scope of work. Estimates of the cost, scope and schedule of the changes will be provided when a change in scope is identified. If there is a change of scope, the simulation consultants will not begin work on the proposed change until the client provides a change order, letter of intent, or e-mail approving the change.

4. The client agrees to provide a signoff of the functional specification.

5. The client agrees to provide a signoff of model completion.

6. Prices do not include travel expenses, which will be invoiced as incurred.

\section{Figure 3: Sample Simulation Terms and Conditions}

A challenge with any simulation project is managing complexity. Simulation is powerful and you can model to the smallest level of detail. Too much detail will slow the model building effort, model testing and validation. Identifying the appropriate level of detail to meet the project objectives is a developed skill. We agree with Sadowksi (1991) that the natural tendency of the novice modeler is to include too much detail, whereas the more experienced modeler tends toward greater abstraction. The functional specification should guide the model builder and help them to provide the right level of detail in the model.

\section{BUILDING THE MODEL}

As with starting anything, beginning to build a simulation model can be overwhelming. With a completed functional specification, the process should be easier. As mentioned, the functional specification will serve as the roadmap for the model building process.

Below are factors to consider when starting the model building process.

- Who will build the model?

- Will there be a user interface (UI) to the model?

- Will data be read into the model? 


\section{Jurishica and Zupick}

- Who will collect the data?

- Where is the data stored?

- How will the model outputs be extracted?

- How will the model be utilized?

- Will there be more than one model or will one be used to analyze all "what-if" scenarios?

If more than one person will be involved in building the model, their roles should be clearly defined at the project start. Project management, data collection, model building and UI development roles will all need to be defined. On small projects, these roles may be the responsibility of only one individual, but on larger, more complex projects, there may be multiple people involved across different teams.

Generally the framework for the input and output of data can be created as the model building process commences. In some cases a custom UI is not necessary and the analyst will choose to change inputs directly in the software application and review the reports directly from the software application. A custom UI can help speed up model experimentation and allow the simulation consultant to easily hand off a model for analysis by someone not familiar with the simulation software application. Simulation consultants who frequently deliver models to clients will likely have a pre-built framework for interfacing with the model. Most common, interfaces are developed in Microsoft Excel, Access or a VB form. If the model and UI will be delivered to the client, special attention should be paid to the usability of the interface along with documentation on how to run the model via the interface.

The UI can also be used as a guide for data collection. The simulation consulting project manager and the client must agree on who is responsible for collecting data to support the model. This role varies. Sometimes the client prefers to assume responsibility and other times a simulation consultant will take the lead. Data collection can be overwhelming and a project bottleneck. Someone must be assigned ownership. It is best practice to list the known data needs and this responsibility in the functional specification.

The model building itself can be divided among more than one individual, however it is imperative that one member of the team be responsible for managing the collaborative effort and for maintaining the model. Whether one or more individuals are building the model logic, it is important to:

- Maintain easy to understand naming conventions.

- Build the model in a modular format.

- Review the model on a consistent basis to ensure that the logic design mimics the real system or reflects a proposed system as closely as possible.

- Provide model documentation.

- Utilize a simple method of version control in order to document model progress as well as to provide a backup version should anything happen.

- Maintain backups of the model versions on multiple machines and/or servers.

Establishing consistent naming conventions throughout the model logic will make it easier to understand, especially if multiple people will be building the model. In Arena, a typical naming convention is to place an alpha prefix before the name of a modeling element. For example, attribute names may begin with "a_" and resource names begin with "r_". No matter what software application is used, it is recommended to establish naming conventions prior to building the model.

A modular approach to model development allows the simulation consultant to keep the model organized and makes it easier to debug as code is appended to the model. The functional specification should help the simulation consulting project manager to identify appropriate sections of the system that may be developed independently. For example, if an emergency department model is going to be built, the model builder might first develop and test the upfront registration process. Once this is code is established and verified, they may move onto the initial nurse and physician assessment portion. The model builder should not attempt to develop the logic for the entire system at once. It is even more important to build 


\section{Jurishica and Zupick}

the model in a modular format when the effort is collaborative. This avoids duplicate model building and makes it easier to copy code from a smaller model to the master project file.

It is advisable to define as many fixed aspects of the model before beginning to define the logic. For example, in Arena defining the resources, variables, attributes and other model elements prior to building the model logic that will reference those elements, will allow for more efficient model development. While Arena allows the user to create elements on the fly, defining them ahead of time keeps the model builder focused on developing logic rather than trying to determine what to call the next resource. A similar approach in other software applications will likely prove useful.

At the beginning of the project, the client and the simulation consulting project manager should agree on a regular schedule for reviewing the model progress. Depending on the project, it may be necessary to meet every other day or once a week to review the modeling efforts. These meetings ensure the project is progressing as expected and on track per the timeline in the functional specification. Reviews also allow the simulation team members to ask questions and get further clarification if necessary. In some cases, the scope of the project may change. It may be necessary to go back to the functional specification and amend the project definition.

Documentation is a must! Documenting the model logic and creating documentation that describes the model and how to run it makes it easier to maintain and update in the future. Table 3 provides common simulation project documentation.

Table 3: Simulation project documentation

\begin{tabular}{|l|l|}
\hline Document & Description \\
\hline Functional Specification & $\begin{array}{l}\text { The functional specification provides a com- } \\
\text { plete overview of the project scope. It is a } \\
\text { roadmap for the project execution. }\end{array}$ \\
\hline Model Logic Documentation & $\begin{array}{l}\text { In the simulation software application, the } \\
\text { model builder must document their code. The } \\
\text { logic, what is does, how it may need to be up- } \\
\text { dated, how it affects other logic and more } \\
\text { should be noted. }\end{array}$ \\
\hline Model Run Documentation & $\begin{array}{l}\text { Documentation on how to use the interface, run } \\
\text { the model, change inputs and review outputs } \\
\text { should be developed. If multiple models are } \\
\text { developed from the project, clear notes on what } \\
\text { each model does should be established. }\end{array}$ \\
\hline Project Analysis Report & $\begin{array}{l}\text { After the experimentation and analysis is com- } \\
\text { plete, a report containing the simulation outputs } \\
\text { for each scenario should be developed. Any } \\
\text { specific recommendations from the study } \\
\text { should be included in the analysis report. }\end{array}$ \\
\hline
\end{tabular}

It is important to save the model frequently and to create versions of the model at various stages of the process. This allows for security backups and the ability to return to a specific stage of the modeling effort if needed for debugging purposes or to create variations of the model. Having the model backed up on more than one machine, a server, or a DVD is also recommended; hard drives crash and laptops are lost or stolen.

Once the model is complete, verification and validation begins. In most cases, the verification has been taking place during the model construction. Verification is ensuring that the model behavior makes sense; entities are moving in the direction they should be and process steps are taking place as expected. The animation will aid in model verification. Validation will be a simulation team effort. The simulation consulting team and the client team must agree that the simulation model outputs are close enough to the 


\section{Jurishica and Zupick}

real system outputs before experimentation. If the model cannot be validated then it cannot be used for proper analysis.

\section{DELIVERING RESULTS}

Once the model is complete and validated, model analysis and experimentation can take place. As part of the functional specification, the simulation consulting project manager and the client should have agreed upon the project deliverables. The simulation consulting team may have agreed to provide a simulation model and UI to the client and the client to take the responsibility of running scenarios and analyzing the results. On the other hand, the consulting team could execute the scenarios defined in the functional specification and provide a written report to the client with the key performance indicators and recommendations from the scenarios. In either situation, the simulation team will need to collaborate to ensure the model experimentation is run and interpreted correctly.

In the case where the model is handed off to the client, it is important to make sure that the contact, who will be running and working the model, knows how to use it. It is critical to formally train the end user and that the model builder has designed an easy to use UI. It is also important to clearly document how to run the model and review the results. Figure 4 is a sample Excel UI for a simulation model. Figure 5 is an example of a VB user form that prompts the end user for inputs. Figure 6 is a web-based interface developed for a user to input and view the results of a simulation model over the web.

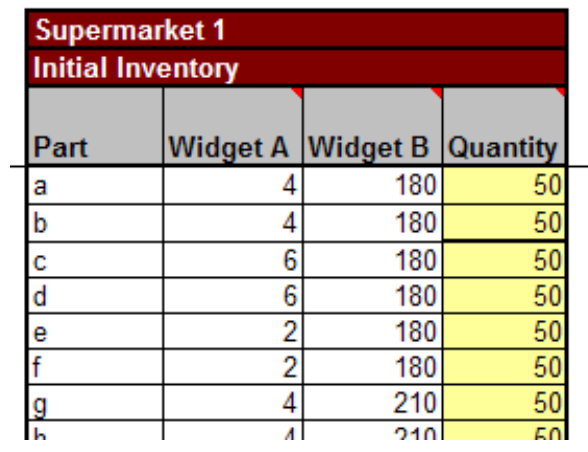

\begin{tabular}{|l|r|r|r|r|r|}
\hline \multicolumn{2}{|l|}{ Buffer Cells } \\
\hline Initial Inventory \\
\hline Part & Widget A & Widget B & Priority & Quantity & Cell \\
\hline a & 4 & 180 & 1 & 0 & 5 \\
\hline b & 4 & 180 & 7 & 0 & 7 \\
\hline c & 6 & 180 & 2 & 0 & 5 \\
\hline$d$ & 6 & 180 & 8 & 0 & 7 \\
\hline e & 2 & 180 & 3 & 0 & 5 \\
\hline $\mathrm{f}$ & 2 & 180 & 9 & 0 & 7 \\
\hline $\mathrm{g}$ & 4 & 210 & 4 & 0 & 5 \\
\hline $\mathrm{h}$ & $\mathrm{A}$ & 210 & 10 & 0 & 7 \\
\hline
\end{tabular}

Figure 4: Excel user interface example

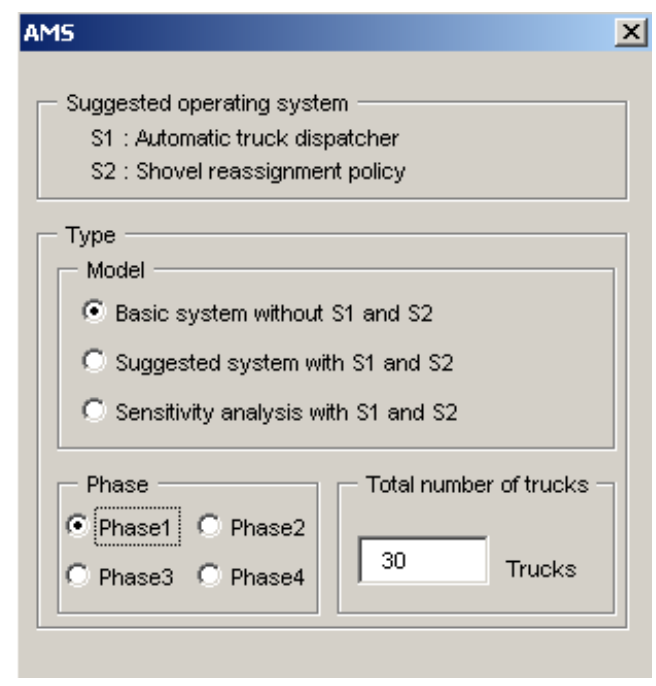

Figure 5: VB user form input example 


\section{Jurishica and Zupick}

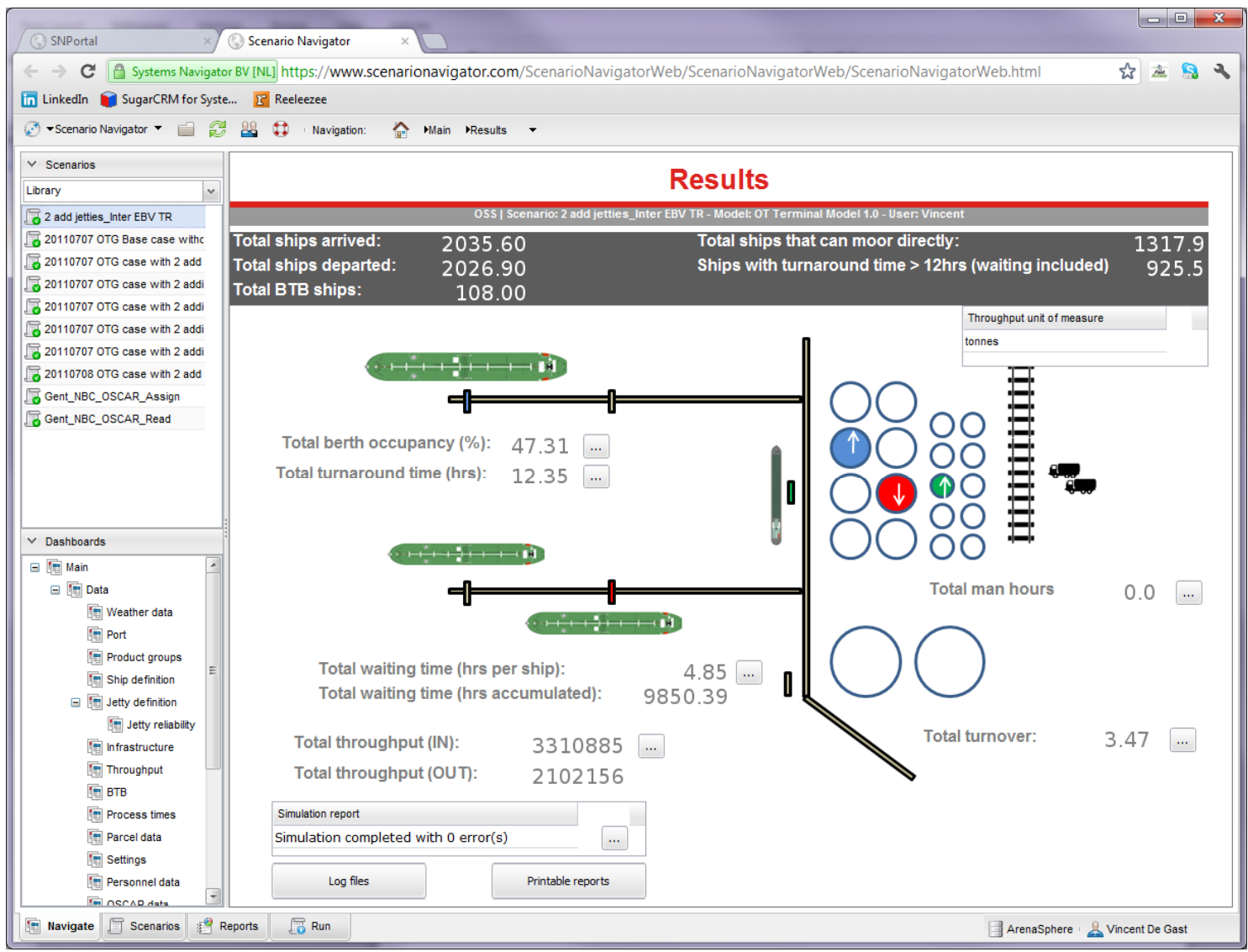

Figure 6: Web-based user interface example (developed by Systems Navigator, www.systemsnavigator.com)

Part of the consulting deliverables may be a model analysis report. In this case, the simulation consulting team agreed to run the scenarios defined in the functional specification and provided a detailed report with the results of the simulation. The analysis report may include, but is not limited to the sections noted in Table 4.

Table 4: Analysis report contents

\begin{tabular}{|l|l|}
\hline Analysis Section & Description \\
\hline Executive Summary & $\begin{array}{l}\text { Provides a brief overview of the project problem, objectives and rec- } \\
\text { ommendations. Someone who is not familiar with the project should } \\
\text { be able to read the executive summary and understand the goals and } \\
\text { conclusion. }\end{array}$ \\
\hline Background & Any necessary background on the project, company and problem. \\
\hline $\begin{array}{l}\text { Model Building and } \\
\text { Validation }\end{array}$ & $\begin{array}{l}\text { This section of the report should address the model building process } \\
\text { and a discussion of the validation process to promote model credibil- } \\
\text { ity (Law 2003). }\end{array}$ \\
\hline $\begin{array}{l}\text { "What-if" Scenario } \\
\text { Results }\end{array}$ & $\begin{array}{l}\text { Provides a thorough analysis of the scenarios that were defined in } \\
\text { the functional specification along with the simulation model results } \\
\text { for the KPIs defined. }\end{array}$ \\
\hline $\begin{array}{l}\text { Conclusions and } \\
\text { Recommendations }\end{array}$ & $\begin{array}{l}\text { Provides analysis and recommendations for the project objectives } \\
\text { based on the scenario results. }\end{array}$ \\
\hline
\end{tabular}




\section{Jurishica and Zupick}

At the end of the project, the functional specification, model analysis report, supporting documentation and simulation model will provide a complete overview of the project. These project files should be preserved by the simulation team as a record of the project.

\section{CONCLUSION}

Executing a simulation project is not trivial and the simulation project will never go exactly as planned. Scope will change, data gathering will be more difficult than initially expected, the model will be challenging to validate and the team will be frustrated at times. Still, establishing a framework for conducting projects and following this framework with rigor will increase the likelihood of success. After each project, the simulation consulting team should discuss what went right and what went wrong. Tools and methodologies should be continuously updated and improved.

\section{REFERENCES}

Balci, O. 2011. "How to Successfully Conduct Large-Scale Modeling and Simulation Projects," In Proceedings of the 2011 Winter Simulation Conference, edited by S. Jain, R. R. Creasey, J. Himmelspach, K. P. White, and M. Fu, 48-55. Piscataway, New Jersey: Institute of Electrical and Electronics Engineers, Inc.

Kelton, D., Sadowski, R., and Swets, N. 2010. Simulation with Arena. 5th ed. New York: McGraw-Hill.

Law, A. 2003. "How to Conduct a Successful Simulation Study," In Proceedings of the 2003 Winter Simulation Conference, edited by S. Chick, P. J. Sanchez, D. Ferrin, and D. J. Morrice, 66-70. Piscataway, New Jersey: Institute of Electrical and Electronics Engineers, Inc.

Sadowski, R. 1991. "Avoiding the Problems and Pitfalls in Simulation,” In Proceedings of the 1991 Winter Simulation Conference, edited by B. L. Nelson, W. D. Kelton and G. M. Clark, 176-182. Piscataway, New Jersey: Institute of Electrical and Electronics Engineers, Inc.

\section{AUTHOR BIOGRAPHIES}

CARLEY JURISHICA studied industrial engineering at Northwestern University. In 2008 she received her Masters of Engineering Management from Northwestern University. She has been working for Rockwell Automation with the Arena simulation software product for over 8 year. She started her Arena career as a simulation consultant, teaching Arena training classes and executing projects for external clientele. From 2008 - 2010 she spent time in a sales role, selling Arena software and services. Currently she is the Arena Product Manager. Her email address is cjjurishica@ra.rockwell.com.

NANCY ZUPICK (formally Swets) received her bachelor's degree in industrial engineering from the University of Pittsburgh. In 1997 she joined Systems Modeling (later acquired by Rockwell Automation) in the technical support group where she worked for over a decade assisting clients with their simulations in a wide array of industries. From 2008-2011 she was the Requirements Analyst for Arena. Currently, she is the Arena Simulation Consulting Manager responsible for a team who provides training, mentoring and turn-key projects to Arena customers. She is also co-author of the $5^{\text {th }}$ edition of the Simulation with Arena textbook. Her email address is nbzupick@ra.rockwell.com. 